\title{
US attitudes to biotechnology show qualified support
}

\section{Washington}

ENTHUSIASM, concern and ambivalence are all part of the US public's attitude to biotechnology, according to a new report by the US Office of Technology Assessment (OTA)". Although 66 per cent of Americans believe that genetic engineering will improve life for everyone, 52 per cent think that improvement may be accompanied by dangers to people or the environment

The report's findings are the result of a study by the Louis Harris and Associates agency, which sampled the views of 1,273 citizens last autumn. Most of the US population thinks it understands the concept of genetic engineering. Although 62 per cent of the public feel that the benefits of new technological and scientific developments outweigh the possible risks,

\section{Anaesthetics display}

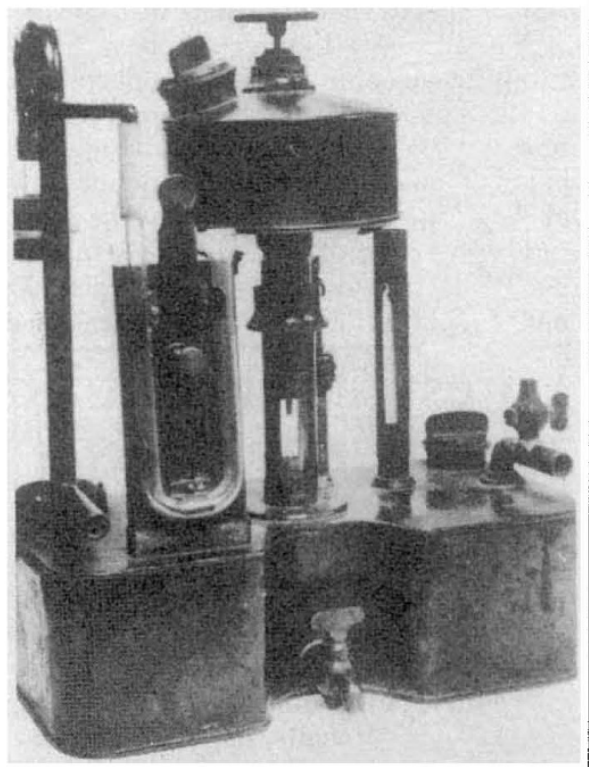

SHIPWAY's warm ether/chloroform intratracheal apparatus, on display at the exhibition "No Laughing Matter: Historical Aspects of Anaesthesia" at the Wellcome Institute for the History of Medicine, 183 Euston Road, London, UK, which opened on Monday this week. The exhibition uses rare archival material to show how the discovery and development of anaesthetics caught the interest of the public and demonstrates the contribution of anaesthetics to medicine and research. In Shipway's apparatus (1916-35), a copper water bath held a waisted chloroform bottle and a vaporizing chamber for ether. Air, with or without oxygen, was passed through the anaesthetic agents by a motorized pump. (Actual size $255 \times 286 \times 285 \mathrm{~mm}$.) the OTA study reveals a relatively widespread belief that biotechnology is inherently dangerous. But fears about biotechnology are generally vague and illdefined, prompting OTA to conclude that the public's beliefs "are not necessarily based on factual information". On the other side, about half of those responding to the survey feel that the risks of genetic engineering have been exaggerated.

Most people are willing to take on relatively high rates of risk to reap the benefits of genetic engineering, the study finds. Slightly over half would approve the use of a genetically engineered product that would significantly increase farm production if the risk of losing a local species of plant or fish were 1 in 1,000 . But the amount of risk must be quantified for most people to approve the use of a biotechnological product in the environment.

Resistance to field trials of new organisms was not as high as critics of biotechnology have suggested. A surprising 67 per cent said they would either approve or not care if a genetically engineered product were field-tested in their community. But people would be more hesitant to approve the dissemination of a biotechnological product on a large scale.

A consistent pattern revealed by the report is that the US public supports potential gains from genetic engineering, but is uneasy with the abstract idea of genetic manipulation. Nearly half the public feel that it is morally wrong to alter the genetic make-up of human cells, but about three-quarters would approve of specific therapeutic applications to reduce someone's risk of developing a fatal disease later in life or to cure a usually fatal disease. Most would even favour genetic therapy on germ-line cells to prevent potentially fatal genetic defects from being passed on, even though the scientific community has been reluctant to open this Pandora's box.

The study uncovers a problem for the government: on the one hand, the public believes that the government is best suited to make regulatory decisions to protect public safety; but on the other, it feels that university scientists, public-health officials or environmental groups are better sources of information on the subject. When asked if they would believe a government agency's assurances of safety over the warnings of an environmental group, most chose the environmentalists. This lack of faith in government agencies may reduce the government's role in public-education efforts.

Carol Ezzell

New Developments in Biotechnology. Public Perceptions of Biotechnology. OTA-BP-BA-45, US Government Printing Office. Washington. DC

\section{New education satellite planned for Europe}

\section{London}

A SATELLITE network linking the centres of excellence in European science teaching is to be launched at the beginning of next year for use in industry and academic institutions. The project, backed by the European Community and five of the principal electronics groups in Europe and the United States, will provide a unique vehicle for advanced education through 'remote learning'.

The network, called PACE, the Programme of Advanced Continuing Education, will offer students at universities or in industry courses that can be credited toward an advanced degree or postdoctoral qualification. It will be modelled on the American National Technological University (NTU), founded in 1985. The programme, which will chiefly benefit students or employees in the applied sciences, has received financial and technical support from companies throughout Europe and the United States. Typically, the network would offer courses on software engineering, microelectronics, materials sciences, telecommunications and artificial intelligence. The service is expected to be carried on a European telecommunications spacecraft and to be given full support by the respective national telecommunication authorities. According to the PACE organizers, the chief suppliers of services or courses to the network will be those in European universities and other higher-educational and scientific institutions "recognized of top quality and as leaders in the field concerned, and the users will be engineers, managers, technicians and scientists who need advanced training and specialist knowledge. The organizers have already established cooperative links with European bodies representing higher education and the professions.

The group will also try to establish agreements in the United States. Although the planning is at an early stage, collaboration with NTU is typical of the links being considered, allowing American postgraduate expertise to be offered to European students.

Britain's Open University, which offers courses to 110,000 students through the public broadcasting network, is finalizing agreements for six programmes, candidates for broadcast across Europe, to be used as pilots to sell its services. The experimental satellite Olympus, scheduled for launch next year, has also attracted the attention of the Open University. An educational channel is to be offered free to suppliers by the European Space Agency. 